\title{
Catheter interventional closure of a large right pulmonary artery-to-left atrial communication in a neonate
}

\author{
Burkamp, Antje ; Ghisla, Renzo ; Knirsch, Walter ; Kretschmar, Oliver ; Balmer, Christian
}

\begin{abstract}
Right pulmonary artery-to-left atrial communication is a rare congenital vascular malformation that results in a right-to-left shunting. This report describes the case history of a neonate with a large right pulmonary artery-to-left atrial connection resulting in cyanosis and severe heart failure who underwent successful early catheter interventional therapy. In the neonate, this lesion can be diagnosed accurately using transthoracic echocardiography. Closure of the communication can be achieved even in infants via percutaneous interventional catheterization with a low procedure-related risk and a good midterm follow-up result.
\end{abstract}

DOI: https://doi.org/10.1007/s00246-012-0262-3

Posted at the Zurich Open Repository and Archive, University of Zurich ZORA URL: https://doi.org/10.5167/uzh-70415

Journal Article

Published Version

Originally published at:

Burkamp, Antje; Ghisla, Renzo; Knirsch, Walter; Kretschmar, Oliver; Balmer, Christian (2012). Catheter interventional closure of a large right pulmonary artery-to-left atrial communication in a neonate. Pediatric Cardiology, 33(8):1440-1442.

DOI: https://doi.org/10.1007/s00246-012-0262-3 


\title{
Catheter Interventional Closure of a Large Right Pulmonary Artery-to-Left Atrial Communication in a Neonate
}

\author{
Antje Burkamp • Renzo Ghisla • Walter Knirsch • \\ Oliver Kretschmar $\cdot$ Christian Balmer
}

Received: 4 December 2011/Accepted: 16 February 2012/Published online: 9 March 2012

(C) Springer Science+Business Media, LLC 2012

\begin{abstract}
Right pulmonary artery-to-left atrial communication is a rare congenital vascular malformation that results in a right-to-left shunting. This report describes the case history of a neonate with a large right pulmonary artery-to-left atrial connection resulting in cyanosis and severe heart failure who underwent successful early catheter interventional therapy. In the neonate, this lesion can be diagnosed accurately using transthoracic echocardiography. Closure of the communication can be achieved even in infants via percutaneous interventional catheterization with a low procedure-related risk and a good midterm follow-up result.
\end{abstract}

Keywords Catheter interventional therapy $\cdot$ Congenital heart defect · Pulmonary artery-to-left atrium

communication $\cdot$ Neonate

One-third of neonatal cyanosis cases are caused by congenital heart defects and it is important to differentiate them from pulmonary disease or persistent fetal circulation [5]. Right pulmonary artery (RPA)-to-left atrium (LA) communication involves a direct connection between the pulmonary artery and the pulmonary vein or LA [11] and is a very uncommon cause of right-to-left shunting. This pathologic vascular communication results in a large shunting of venous blood to the arterial side, leading to both cyanosis and volume overload.

\footnotetext{
A. Burkamp · W. Knirsch · O. Kretschmar · C. Balmer ( $\square)$ Department of Pediatric Cardiology, University Children's Hospital Zurich, Steinwiesstrasse 75, 8032 Zurich, Switzerland e-mail: christian.balmer@kispi.uzh.ch

R. Ghisla

Children's Hospital, St. Gallen, Switzerland
}

\section{Case Report}

A female term neonate with a birth weight of $3 \mathrm{~kg}$ and $620 \mathrm{~g}$ presented $14 \mathrm{~h}$ postnatally with central cyanosis and clinical signs of respiratory distress. An echocardiogram showed a large RPA-LA communication from the proximal RPA to the roof of the LA (Fig. 1). The LA and the left ventricle were dilated, and left ventricular function was impaired (ejection fraction, 33\%).

The patient's condition improved and stabilized after initiation of continuous epinephrine and milrinone administered intravenously. After 6 days, cardiac catheterization was performed with the patient under general anesthesia via a transfemoral venous approach using a 5-Fr introducer sheath. The size and anatomy of the fistula were identified and measured by a selective pulmonary angiogram (Fig. 2).

Due to the shunt volume, the diameter of the proximal RPA was double that of the left pulmonary artery. The fistula itself measured 9-mm at the pulmonary end, narrowed to $2.2-\mathrm{mm}$, and widened again to $9-\mathrm{mm}$ at the atrial end at the roof of the LA.

The communication was entered from the pulmonary arterial side with an $0.018 \mathrm{in}$. wire. Through the 5-Fr sheath and across the wire, a flexible introducer catheter was advanced into the fistula. Successful closure then was performed with a detachable patent arterial duct (PDA) coil (7 $\times$ 6-mm, Nit-Occlud; pfm, Cologne, Germany) from the pulmonary arterial side. Three loops of the coil were placed into the LA, and the remaining loops were placed into the fistula and the RPA.

After confirmation that the positioning of the device was stable and the flow of the RPA and LA was unimpaired (via a contrast injection through the introducer catheter and a transthoracic echocardiography), the coil was released. A final angiogram showed an optimal coil position without any 


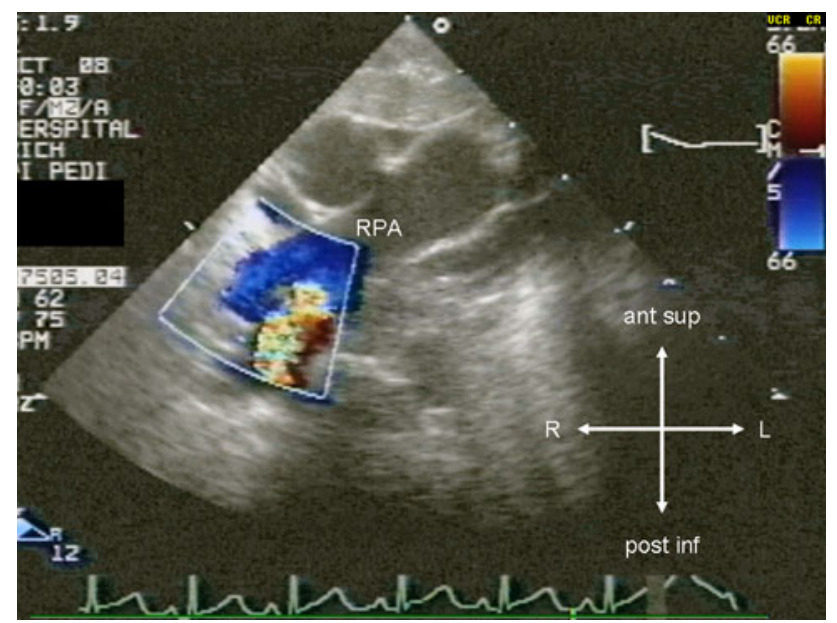

Fig. 1 Preinterventional transthoracic echocardiography. The modified high parasternal short-axis view shows the right pulmonary artery (RPA). Laminar flow into the peripheral RPA and turbulant flow through the communication into the left atrium can be seen with color flow Doppler imaging

significant residual shunting (Fig. 3). The oxygen saturation rose immediately to $99 \%$. During the following days, the size of all the cardiac chambers completely normalized, and the patient gradually recovered from heart failure.

The patient was discharged home at the age of 2 weeks and was treated with aspirin for a further 6 months to avoid thromboembolic complications during device endothelialization. After 2 years, the patient was free of any cardiac symptoms and showed normal body growth and development. The size of all the cardiac chambers had completely normalized.

\section{Discussion}

Although extremely rare, RPA-LA communication is a congenital malformation that should be considered in the differential diagnosis of neonatal cyanosis. Published descriptions show reported cases since 1960 [6], and a review of the literature dates 72 case publications at the end of 2010 [8]. With regard to broadening of the spectrum, classification of anatomic variants has changed [3]. Histologic examination has shown a characteristic morphology of the RPA-LA communication, which suggests, with some variability in the aneurysm formation, that it has a clinical entity of its own and thus differs from the more common pulmonary arteriovenous fistula [9].

The spectrum of RPA-LA communication includes a heterogeneous group of cases with potentially different embryonic development [2]. It is hypothesized that the lesion results from a fistula that forms during early embryonic development between the pulmonary artery and one of the main pulmonary veins, which later becomes incorporated into the wall of the LA during atrial enlargement.

At histologic examination, the sac showed an inner layer of endothelial cells and elastin tissues and an outer layer of muscular tissue, resembling more a vessel than a typical arteriovenous fistula [2]. In our patient, drainage of the pulmonary veins was normal without aneurysm formation as seen in the most common type 1 disorder.

Only large fistulas present in the neonatal period. Cyanosis resulting from a large right-to-left shunting usually is the main feature [1]. For neonates, full and accurate description and delineation of all morphologic and hemodynamic aspects of the RPA-LA communication can be performed at the bedside exclusively using transthoracic echocardiography.

Closure of the RPA-LA communication is indicated to eliminate hemodynamically relevant shunting and to avoid long-term complications such as transient ischemic attacks, cerebral infarction or abscess, infective endarteritis/ endocarditis, and progressive aneurysmal growth of the
Fig. 2 Angiogram before closure of the communication. a Frontal view. b Lateral view. The catheter is positioned antegradely through the right pulmonary artery (RPA), and the communication (arrows) is into the left atrium (LA). $L V$ left ventricle, $L P A$ left pulmonary artery
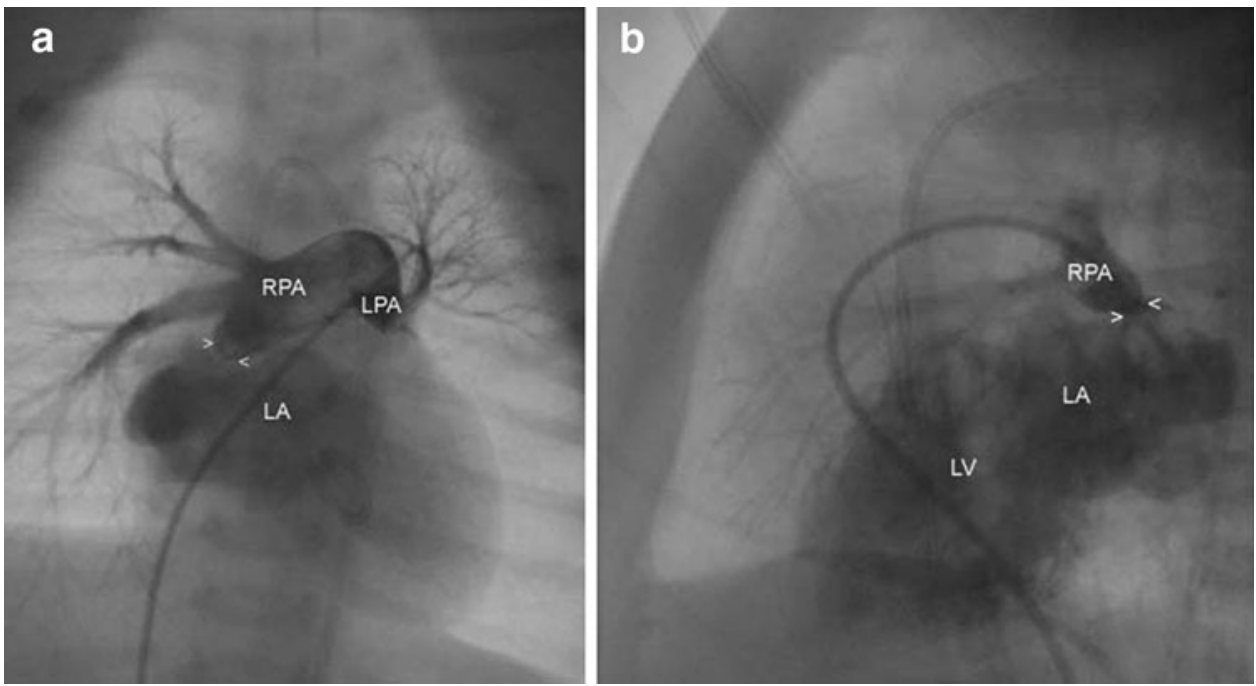
Fig. 3 Angiogram after closure of the communication. a Frontal view showing the coil still attached to the delivery system. b Lateral view showing the coil detached and in the final position. $\mathbf{c}$ Magnified picture of a pfm coil. $R A$ right atrium. $P D A$ patent arterial duct

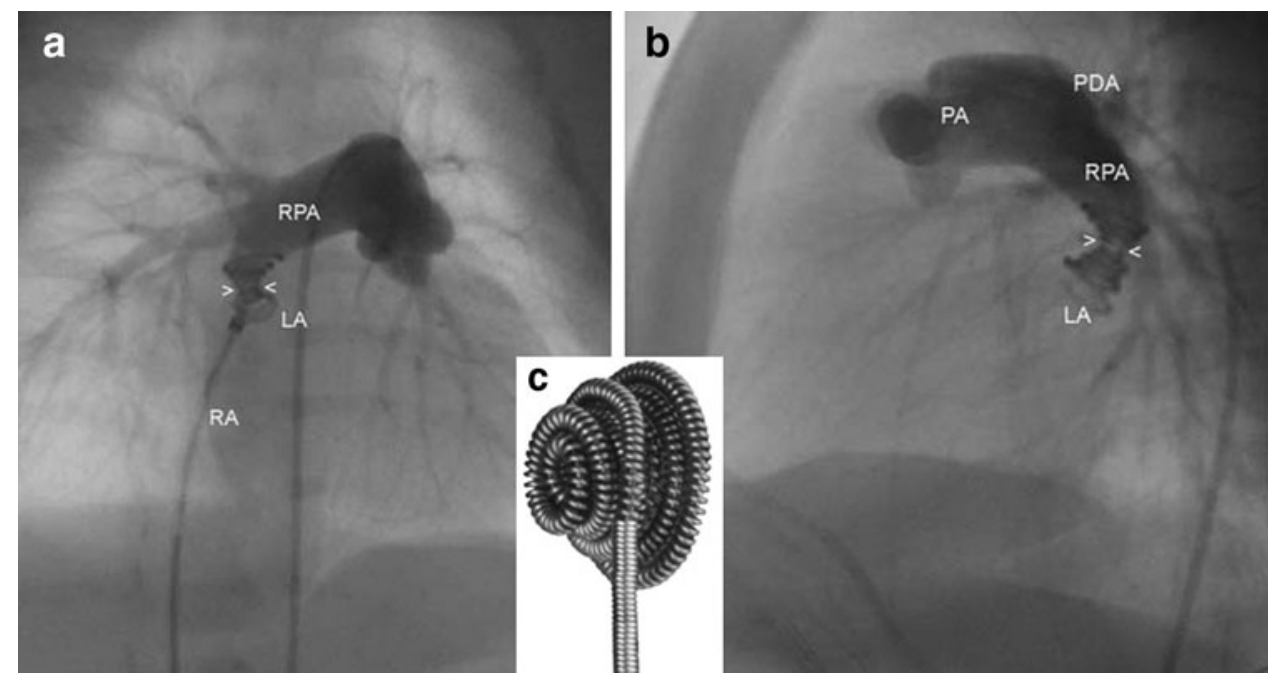

abnormal vessel, with possible rupture [12]. The communication can be addressed successfully by means of percutaneous catheter-based interventional device closure in neonates and older children [10].

The Nitocclud coil was originally designed for closure of the PDA and normally results in closure rates of $94 \%$ in neonatal PDAs [4]. Its attractive diabolo-like shape and its soft recoil of the nitinol wire, which causes only minimal pressure on the surrounding tissue, were the reasons why it was chosen for the reported patient. It can be implanted easily via a 5-Fr sheath, with a low risk of post-interventional vessel damage (i.e., thrombosis of the femoral vessels) even in neonates. In some patients with very large RPA-LA communications, surgical closure is appropriate.

The long-term prognosis of patients with RPA-LA communication is favorable [7]. Late detection of the fistula and hypoplasia of the peripheral pulmonary arteries are potential risk factors for an adverse outcome.

\section{References}

1. Bockeria L, Podzolkov V, Makhachev O, Kim A (2010) Congenital direct communication between the right pulmonary artery and the left atrium: anatomic variations and surgical experience. Interact CardioVasc Thorac Surg 10:114-115

2. Chowdhury UK, Kothari SS, Airan B, Subramaniam KG, Venugopal P (2005) Right pulmonary artery-to-left atrium communication. Ann Thorac Surg 80:365-370
3. De Souza e Silva NA, Giuliani ER, Ritter DG, Davis GD, Pluth JR (1974) Communication between right pulmonary artery and left atrium. Am J Cardiology 34:857-863

4. Dimas VV, Takao C, Ing FF, Mattamal R, Nugent AW, Grifka RG, Mullins CE, Justino H (2010) Outcomes of transcatheter occlusion of patent ductus arteriosus in infants weighing $<6 \mathrm{~kg}$. J Am Coll Cardiol Intv 3:1295-1299

5. Duff DF, McNamara DG (1998) History and physical examination of the cardiovascular system. In: Garson A Jr, Bricker TM, Fisher DJ, Neish SR (eds) The science and practice of pediatric cardiology. Williams and Wilkins, Baltimore, p 693

6. Friedlich A, Bing RJ, Blount SG Jr (1950) Physiological studies in congenital heart disease: IX. Circulatory dynamics in the anomalies of venous return to the heart including pulmonary arteriovenous fistula. Bull Johns Hopkins Hosp 86:20-57

7. Luo GH, Ma WG, Huang LJ, Zhu XD (2011) Surgical and transcatheter closure of right pulmonary artery-to-left atrial fistula. J Card Surg 26:130-134

8. Margaryan R, Arcieri L, Cantinotti M, Murzi B (2010) Surgical closure of big pulmonary artery-left atrial fistula. Interact CardioVasc Thorac Surg 1:113-114

9. Ramakrishnan S, Shivdas S, Kothari SS (2010) Transseptal closure of a right pulmonary artery to left atrial communication. Cathet Cardiovasc Intervent 75:1096-1099

10. Slack MC, Jedeikin R, John JS (2000) Transcatheter coil closure of a right pulmonary artery-to-left atrial fistula in an ill neonate. Cathet Cardiovasc Intervent 50:330-333

11. Wingen M, Günther RW (2001) Pulmonary arteriovenous malformations. Deutsches Ärzteblatt 20:1326-1330

12. Zeebregts CJ, Nijveld A, Lam J, van Oort AM, Lacquet LK (1997) Surgical treatment of a fistula between the right pulmonary artery and the left atrium: presentation of two cases and review of literature. Eur J Cardiothorac Surg 11:1056-1061 